\title{
Seasonal Variation in Sudden Death among Japanese Workers: Why are There Peaks in Spring and Winter?
}

\author{
Tsutomu Hoshuyama, Ken Takahashi and Toshiteru Okubo \\ Department of Environmental Epidemiology, Institute of Industrial Ecological Sciences, \\ University of Occupational and Environmental Health
}

\begin{abstract}
Seasonal Variation in Sudden Death among Japanese Workers: Why are There Peaks in Spring and Winter?: Tsutomu Hoshurama, et al. Department of Environmental Epidemiology, Institute of Industrial Ecological Sciences, University of Occupational and Environmental Health-These days particular attention is being paid to sudden death among Japanese workers, an issue requiring an urgent solution. This study describes the seasonal variation in sudden death, and examines the synchronization of death with workers' busy period. Questionnaires were sent to occupational health physicians belonging to a representative sample of large-scale working establishments in Japan. Inquired were cause, date, and other demographic information on sudden death cases that had occurred in each establishment from 1988 to 1992 . The seasonal variation in sudden death was analyzed by age, cause of death, and industry, and synchronization of death with the period of settlement of accounts (SA) of the establishment was examined. Of 488 male sudden deaths reported, 362 were categorized as being of cardiovascular origin. Both the 488 cases and the 362 cardiac cases had two peaks of occurrence in MarchApril and in November-December with statistical significance $(p<0.01)$. Of the 201 cases aged $45-54$, $70(35 \%)$ died within two months of the SA. The peak in March-April may be accounted for by an increased number of sudden deaths among workers aged 45-54, whereas the peak in November-December may be accounted for by an increased number of sudden deaths among the entire worker population studied. Because both peaks were associated with busier periods for workers in Japan, work environmental factors may affect the seasonal variation resulting in such a distinctive shape of the curve for sudden death among workers. (J Occup Health 1999; 41: 244-252)
\end{abstract}

Received Feb 8, 1999; Accepted July 19, 1999

Correspondence to: T. Hoshuyama, Department of Environmental Epidemiology, Institute of Industrial Ecological Sciences, University of Occupational and Environmental Health, 1-1 Iseigaoka, Yahatanishi, Kitakyushu, 807-8555, Japan
Keywords: Epidemiology, Questionnaire, Sudden death, Seasonal variation, Workers, Middle-aged, Settlement of accounts, Stress

These days, much attention is being focused on sudden death among Japanese workers. In particular, death due to occupational-stress-related cardiovascular attack, mainly triggered by long working hours, i.e., karoshi, is of rising social and academic concern ${ }^{1}$. However, very few epidemiologic surveys have been carried out on sudden death among Japanese workers. In a previous study, we reported that cases of sudden death increased with age and included death from cardiovascular origins at a rate of about $80 \%$ of the 141 sudden death cases among male Japanese workers ${ }^{2}$. In a 6-year follow-up study in a Japanese electric company with 20,000 male workers, Sakai reported descriptive epidemiology on 39 sudden death cases which also increased with age ${ }^{3}$. The epidemiology of sudden death among Japanese workers requires further study.

Willich et al. stated that investigation of circadian and seasonal variation in the occurrence of myocardial infarction and sudden cardiac death could be of great help in the study of causal mechanisms in such cardiac events ${ }^{4)}$. We reported a seasonal variation showing double peaks of occurrence of sudden death in April and December ${ }^{2}$. In Japan, many workers feel busy and stressful around April and around December. This may be partly related to the fact that many Japanese corporations have set the period for the settlement of accounts (SA) in March, the fiscal-year end in Japan, and workers may feel more pressed than usual to raise their work performance. In addition, December is called shiwasu in Japanese, implying that it is busiest month. The original meaning of the word is "the month of busy priests who must run about attending to religious services at the calendar-year end"5). Such psychological stress may increase the risk of cardiovascular diseases for workers in these periods. The chronological pattern of occurrence of various diseases should therefore be 
investigated to clarify the etiologic relationship.

The present study aims to describe the epidemiologic characteristics, especially those related to the seasonal variations of sudden death among the working population in large-scale establishments with 1,000 or more workers. In particular, we examined the synchronization of the sudden death cases with the period of SA of the establishments investigated and the natural calendar.

\section{Materials and Methods}

\section{Study population and information collected}

From the reports of the 1991 Establishment Census conducted by the Statistic Bureau, Management and Coordination Agency (Soumucho-Toukeikyoku, in Japanese $)^{6)}$, we selected a total of 1,300 establishments. This is the entire number of establishments in Japan with 1,000 workers or more. Questionnaires were mailed to the occupational health physicians of each establishment to obtain information on sudden death cases which occurred in each establishment between January 1, 1988 and December 31, 1992. Information requested included gender, date of birth, date of death, time of death, all descriptions regarding cause of death which were included in the death certificate of each case, and the interval between onset of the acute symptoms related to the death and death. Post-mortem information was also requested if it was available. When death certification was not available, the information was requested from other medical records that could specify the cause of death.

We coded the underlying cause of death of the cases by the 9 th revision of the International Classification of Diseases (ICD-9), and categorized them into cardiovascular diseases coded 401-405, 410-414, 422$429,441-444$, and 456; cercbrovascular diseases coded $430-437$.

Of the 1,300 establishments, 95 had participated in the previous survey noted above ${ }^{2)}$. According to the results, 31 establishments had one or more sudden death cases and the others had none during the study periods. To avoid re-reporting of the cases, we informed the 31 establishments that they need not report the cases again.

\section{Definition of sudden death}

The definition of sudden death used was a natural death occurring within $24 \mathrm{~h}$ after the onset of acute symptoms in a person who had had no restriction on his daily work activity prior to the onset. This definition is consistent with that of $\mathrm{WHO}^{7)}$.

\section{Statistical analysis of seasonal variation}

In general, the usual chi-square test does not aim to define secular trend patterns in the data. It must be supplemented by more specific tests ${ }^{\mathrm{g}}$. Thus, to evaluate the seasonal variation in the occurrence of sudden death, we employed the non-parametric method introduced by Freedman with Kolmogorov-Smirnov type statistics. The method is applicable to both when the incidence or mortality data for several years are compressed to the form of a series of 12 monthly totals and to when no long-term trend cxists during the study period ${ }^{\text {?) }}$.

Briefly, the Freedman's method is as follows: Supposing N subjects in the sample that the time of occurrence of the event in question is, for the ith patient, $t_{i}(i=1, \ldots, N)$ where $t_{i}$ is the time from the beginning of the year, these two functions, $F(t)$ and $F_{N}(t)$, are given. $F(t)$ is the cumulative distribution function, $F(t)=P\left(t_{i} \leqq\right.$ $t)=t / 365 \frac{1}{4} . F_{v}(t)$ is the sample cumulative distribution function, $F_{N}(t)=j / N$, where $j$ is the number of cases with $t_{i} \leqq t$. Since the one-sided Kolmogorov-Smirnov type statistics, $\mathrm{D}_{\mathrm{N}}{ }^{+}$and $\mathrm{D}_{\mathrm{N}}{ }^{-}$, are defined by $\mathrm{D}_{\mathrm{N}}{ }^{+}=\max \left(\mathrm{F}_{\mathrm{N}}(\mathrm{t})\right.$ $\mathrm{F}(\mathrm{t})), 0 \leqq \mathrm{t} \leqq 365 \frac{1}{4}$, and $\mathrm{D}_{\mathrm{N}}{ }^{-}=\operatorname{lmin}\left(\mathrm{F}_{\mathrm{N}}(\mathrm{t})-\mathrm{F}(\mathrm{t})\right) \mid, 0 \leqq \mathrm{t} \leqq$ $365 \frac{1}{4}, V_{N}$ is redefined as $V_{N}=D_{N}+D_{N}{ }^{-}$with the important property of independence of the beginning point from which $t$ is measured. When the data are grouped into 12 months, the $\mathrm{V}_{\mathrm{N}}$ can be redefined as $\mathrm{V}_{\mathrm{N}}=\mathrm{D}_{\mathrm{N}}{ }^{+}+\mathrm{D}_{\mathrm{N}}{ }^{-}=$ $\max \left(F_{N}(t)-F(t)\right)+\left|\min \left(F_{N}(t)-F(t)\right)\right|, 0 \leqq t \leqq 12$, because both the cumulative distribution function, $F$, and the sample cumulative distribution function, $F_{N}$, become a step function with 12 steps. Using the table of asymptotic distribution of $\mathrm{V}_{\mathrm{V}}$, statistical significance can be assessed for a certain data grouped into 12 months ${ }^{9}$.

\section{Synchronization of the sudden deaths with the workers busy periods}

In order to examine the synchronization of the sudden deaths and the workers' busy periods, we focused on the numerical difference between the month of sudden death and the month of SA for each case. By subtracting the number of the calendar month ( 1 for January, 2 for February, and so forth) of SA from the calendar month of sudden death, the relationship was expressed as $-6,-$ $5, \ldots, 0,+1,+2, \ldots$, or +5 fixing the month of SA to position zero. For example, if sudden death occurred on July 18, 1990, and the month for SA was set in March in his establishment, the difference would be $+4(=7-3)$. If the worker died on Nov. 20, 1992, and the month for SA was set in December in his establishment, the difference would be $-1(-11-12)$. The month of SA was determined for each of the 611 establishments that validly responded to the questionnaires as described below ${ }^{10-12)}$.

We compared the monthly difference between sudden death and SA by age category (44 or younger, $45-54$, and 55 or older), by cause of death (cardiovascular disease, cerebrovascular disease, and others), and by type of industry (manufacturing or not manufacturing). After categorizing cases into two groups by whether the SA of the establishment was in March or not, the monthly difference was also compared. 


\section{Results}

Of the 1,293 establishments ( 7 were excluded due to their leaving no trace), 611 validly answered the questionnaires for a response rate of $47.3 \%$. Regarding types of industry, manufacturing industries numbered 445 $(72.8 \%)$ of the respondents (Table 1). Categorizing the 557 establishments with known numbers of total workers, $380(68.2 \%)$ were among those with $1,000-2,999$ workers, $58(10.4 \%)$ among those with 3,000-4,999 workers, $45(8.1 \%)$ among those with 5,000-9,999 workers, and $17(3.1 \%)$ among those with 10,000 or more workers. The other 57 establishments $(10.2 \%)$ were categorized into those with 999 or fewer workers. The mean number of workers $( \pm \mathrm{SD})$ was $2,696( \pm 3,385)$, and the median was 1,679 . The range of number of workers was 106 to 51,000 .

Of a total of 502 sudden death cases reported including 488 males, 13 females, and 1 sex-undistinguished, 488 male cases comprised the study subjects. Mean age $( \pm$ SD) at death was $47.9( \pm 10.0)$ years.

Table 2 shows the distribution of causes of death by age category among the 488 subjects. As for the causes of death, cardiovascular diseases were reported in 362 cases $(74.3 \%)$, cerebrovascular diseases in 84 cases $(17.2 \%)$, and other diseases in 26 cases $(5.3 \%)$. As for the age at death, 212 were $45-54$ yr (43.4\%), 159 were $44 \mathrm{yr}$ or younger $(32.6 \%)$, and 116 were $55 \mathrm{yr}$ or older (23.8\%). Post-mortem information was available for only 27 cases $(5.5 \%)$ which included 22 cardiovascular diseases, three cerebrovascular diseases, one other disease, and one unknown origin, as the cause of death.

Figure 1 shows the seasonal variation in occurrence of sudden death of the 488 subjects, 362 cardiovascular cases and 212 cases aged 45-54. For all cases, two peaks can be identified in March-April and in November-December. Fifty-two cases $(10.7 \%)$, the highest number, occurred in April, forty-eight (9.8\%) in December, and forty-seven
(9.6\%) in March and November. For the cardiovascular cases and the cases aged 45-54, a peak was also found in March-April, and a smaller one in November-December. Cardiovascular cases accounted for about $70-80 \%$ of each of the monthly totals. On the other hand, cases aged 4554 accounted for uneven percentages of each of the totals, from $32 \%(11 / 34)$ in June to $60 \%(25 / 42)$ in May. The Freedman's non-parametric method produced the values of $\mathrm{V}_{\mathrm{N}}, 0.092,0.091$, and 0.125 , for all cases, the cardiovascular cases, and the cases aged 45-54, respectively, which all indicated statistically significant departure from uniform distribution $(p<0.01)$.

Table 3 shows the distribution of months for $\mathrm{SA}$ among the 611 establishments. Of the 466 workers with identified months for SA, 367 (78.8\%) were employed in establishments with March as the month for SA. Also, of the 487 establishments with identified months for SA, 393 (80.7\%) had March as the month for SA.

Figure 2 shows the monthly difference between sudden death and the SA of each case's establishment for all 466 sudden death cases, 349 cardiovascular cases, and 201 cases aged $45-54$. For all cases, double peaks were found at positions -4 and -3 , and at positions +1 and +2 . One hundred cases $(21.5 \%)$ were included in the former and eighty-seven cases (18.7\%) in the latter period. For the cardiovascular cases, double peaks were found in the same periods as for all the cases. On the contrary, for the cases aged $45-54$, the highest peak was found in the period corresponding to positions zero, +1 , and +2 .

Figure 3 shows the monthly difference between sudden death and the SA of each case's establishment among the workers whose SAs were in March $(n=367)$ and the workers whose SAs were in months other than March $(\mathbf{n}=99)$. In the former groups, 101 cases $(27.5 \%)$ concentrated in the period corresponding to positions zero, +1 , and +2 . In particular, 60 cases of the workers aged 45-54 were concentrated in the same periods, which accounted for $35.9 \%$ of the total number of the workers

Table 1. Distribution of industry of study subjects and respondents

\begin{tabular}{lrr} 
& Study subjects $(\%)$ & Respondents $(\%)$ \\
\hline Agriculture, forestry, and fisheries & $1(0.1)$ & $1(0.2)$ \\
Mining & $3(0.2)$ & $1(0.2)$ \\
Construction & $41(3.2)$ & $12(2.0)$ \\
Manufacturing & $836(64.7)$ & $445(72.8)$ \\
Electricity, gas, heat supply and water & $13(1.0)$ & $8(1.3)$ \\
Transport and communication & $48(3.7)$ & $13(2.1)$ \\
Merchandising & $103(7.9)$ & $40(6.6)$ \\
Financing and insurance & $62(4.8)$ & $15(2.5)$ \\
Real estate & $1(0.1)$ & $0(0.0)$ \\
Services & $185(14.3)$ & $76(12.4)$ \\
\hline Total $(\%)$ & $1293(100.0)$ & $611(100.0)$ \\
\hline
\end{tabular}


Table 2. Cause of death by age category among 488 male sudden death cases

\begin{tabular}{|c|c|c|c|c|c|c|c|}
\hline \multirow{2}{*}{$\begin{array}{l}\text { Disease } \\
\text { category }\end{array}$} & \multirow{2}{*}{ ICD-9 } & \multirow{2}{*}{ Classified diseases } & \multicolumn{5}{|c|}{ Age category (years) } \\
\hline & & & -44 & $45-54$ & $55-$ & unknown & TOTAL(\%) \\
\hline Cardiovascular & 401 & Primary hypertension & 1 & 2 & 2 & 0 & $5(1.0)$ \\
\hline \multirow[t]{16}{*}{ Diseases } & 405 & Secondary hypertension & 1 & 0 & 0 & 0 & $1(0.2)$ \\
\hline & 410 & Acute myocardial infarction & 17 & 35 & 33 & 0 & $85(17.7)$ \\
\hline & 411 & Other acute or subacute ischemic heart diseases & 0 & 2 & 2 & 0 & $4(0.8)$ \\
\hline & 413 & Angina pectoris & 1 & 1 & 2 & 0 & $4(0.8)$ \\
\hline & 414 & Other forms of chronic ischemic heart diseases & 1 & 1 & 2 & 1 & $5(1.0)$ \\
\hline & 422 & Acute myocarditis & 1 & 0 & 0 & 0 & $1(0.2)$ \\
\hline & 424 & Other diseases of endocardium & 0 & 2 & 0 & 0 & $2(0.4)$ \\
\hline & 425 & Cardiomyopathy & 1 & 1 & 1 & 0 & $3(0.6)$ \\
\hline & 426 & Conduction disorders & 1 & 0 & 0 & 0 & $1(0.2)$ \\
\hline & 427 & Cardiac arrhythmias & 2 & 1 & 0 & 0 & $3(0.6)$ \\
\hline & 428 & Heart failure & 88 & 102 & 46 & 0 & $236(49.1)$ \\
\hline & 429 & $\begin{array}{l}\text { Complications and ill-defined descriptions } \\
\text { of heart diseases }\end{array}$ & 2 & 2 & 0 & 0 & $4(0.8)$ \\
\hline & 441 & Aortic aneurysm & 1 & 1 & 4 & 0 & $6(1.2)$ \\
\hline & 444 & Arterial embolism and thrombosis & 0 & 1 & 0 & 0 & $1(0.2)$ \\
\hline & 456 & Varicose veins of other sites & 0 & 1 & 0 & 0 & $1(0.2)$ \\
\hline & \multicolumn{2}{|l|}{ Subtotal } & 117 & 152 & 92 & 1 & $362(74.3)$ \\
\hline \multirow{5}{*}{$\begin{array}{l}\text { Cerebrovascula } \\
\text { Diseases }\end{array}$} & 430 & Subarachnoid hemorrhage & 10 & 22 & 3 & 0 & $35(7.3)$ \\
\hline & 431 & Intracerebral hemorrhage & 12 & 19 & 12 & 0 & $43(8.9)$ \\
\hline & 434 & Occlusion and stenosis of cerebral arteries & 0 & 1 & 0 & 0 & $1(0.2)$ \\
\hline & 437 & Other and unspecified cerebrovascular diseases & 2 & 0 & 3 & $\mathbf{0}$ & $5(1.0)$ \\
\hline & \multicolumn{2}{|l|}{ Subtotal } & 24 & 42 & 18 & 0 & $84(17.2)$ \\
\hline Other & 250 & Diabetes mellitus & 2 & 0 & 0 & 0 & $2(0.4)$ \\
\hline \multirow[t]{10}{*}{ Diseases } & 254 & Diseases of thymus & 1 & 0 & 0 & 0 & $1(0.2)$ \\
\hline & 303 & $\begin{array}{l}\text { Mental and behavioural disorders due to use } \\
\text { of alcohol }\end{array}$ & 0 & 0 & 1 & 0 & $1(0.2)$ \\
\hline & 486 & Pneumonia, organism unspecified & 0 & 2 & 0 & 0 & $2(0.4)$ \\
\hline & 493 & Asthma & 6 & 3 & 1 & 0 & $10(2.1)$ \\
\hline & 518 & Other lung diseases & 0 & 1 & 0 & 0 & $1(0.2)$ \\
\hline & 519 & Other diseases of the respiratory system & 1 & 2 & 1 & 0 & $4(0.8)$ \\
\hline & 528 & Stomatitis and related lesions & 0 & 1 & 0 & 0 & $1(0.2)$ \\
\hline & 531 & Gastric ulcer & 0 & 1 & 1 & 0 & $2(0.4)$ \\
\hline & 570 & Acute hepatic failure & 0 & 2 & 0 & 0 & $2(0.4)$ \\
\hline & \multicolumn{2}{|c|}{ Subtotal } & 10 & 12 & 4 & 0 & $26(5.3)$ \\
\hline Cause & 798 & Sudden death, cause unknown & 2 & 1 & 1 & 0 & $4(0.8)$ \\
\hline \multirow[t]{2}{*}{ Unknown } & 799 & Other ill-defined and unspecified causes of mortality & 6 & 5 & 1 & 0 & $12(2.5)$ \\
\hline & \multicolumn{2}{|l|}{ Subtotal } & 8 & 6 & 2 & 0 & $16(3.3)$ \\
\hline \multicolumn{3}{|l|}{ Total $(\%)$} & $\begin{array}{c}159 \\
(32.6)\end{array}$ & $\begin{array}{c}212 \\
(43.4)\end{array}$ & $\begin{array}{c}116 \\
(23.8)\end{array}$ & $\begin{array}{c}1 \\
(0.2)\end{array}$ & $\begin{array}{c}488 \\
(100.0)\end{array}$ \\
\hline
\end{tabular}


60

52

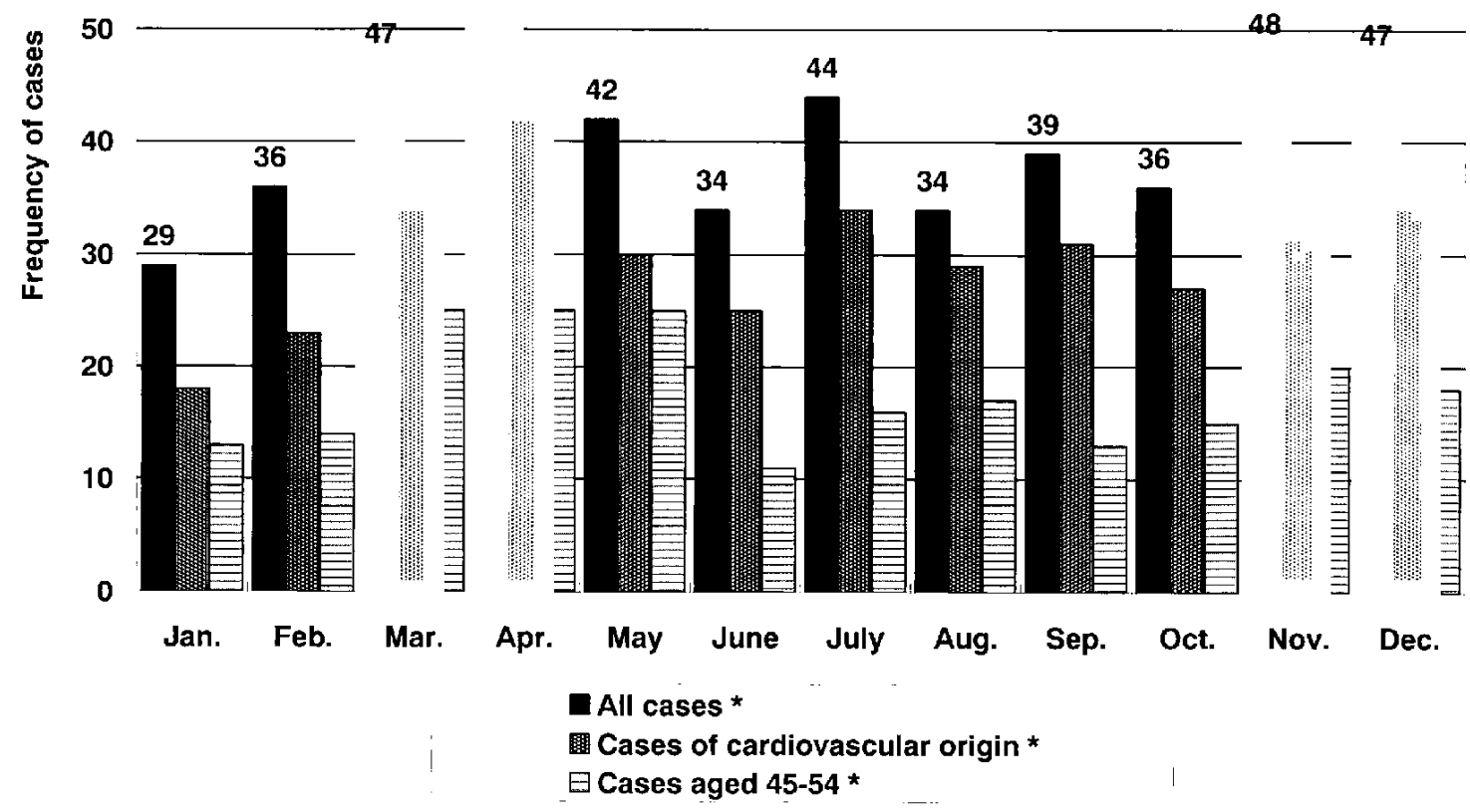

Fig. 1. Seasonal variation in frequency of sudden death among Japanese workers in 1988-1992(*: p<0.01, by Freedman's method).

Table 3. Month for settlement of accounts of 611 establishments according to type of industry

\begin{tabular}{|c|c|c|c|c|c|c|c|c|c|c|c|c|c|c|}
\hline & Jan & Feb & Mar & Apr & May & June & July & Aug & Sept & Oct & Nov & Dec & unknown & TOTAL $(\%)$ \\
\hline Agriculture, forestry, and fisheries & 0 & 0 & 1 & 0 & 0 & 0 & 0 & 0 & 0 & 0 & 0 & 0 & 0 & $1(0.2)$ \\
\hline Mining & 0 & 0 & 0 & 0 & 0 & 0 & 0 & 0 & 0 & 0 & 0 & 0 & 1 & $1(0.2)$ \\
\hline Construction & 0 & 0 & 7 & 0 & 0 & 0 & 0 & 0 & 3 & 0 & 0 & 0 & 0 & $12(2.0)$ \\
\hline Manufacturing & 0 & 3 & 323 & 2 & 1 & 14 & 0 & 1 & 4 & 8 & 8 & 42 & 39 & $445(72.8)$ \\
\hline Electricity, gas, heat supply and water & 0 & 0 & 8 & 0 & 0 & 0 & 0 & 0 & 0 & 0 & 0 & 0 & 0 & $8(1.3)$ \\
\hline Transport and communication & 0 & 2 & 12 & 0 & 0 & 0 & 0 & 0 & 0 & 0 & 0 & 0 & 0 & $13(2.1)$ \\
\hline Merchandising & 0 & 25 & 9 & 0 & 0 & 1 & 0 & 0 & 0 & 0 & 0 & 3 & 2 & $40(6.6)$ \\
\hline Financing and insurance & 0 & 0 & 11 & 0 & 0 & 0 & 0 & 0 & 0 & 0 & 1 & 1 & 2 & $15(2.5)$ \\
\hline Real estate & 0 & 0 & 0 & 0 & 0 & 0 & 0 & 0 & 0 & 0 & 0 & 0 & 0 & $0(0.0)$ \\
\hline Services & 0 & l & 22 & 0 & 0 & 0 & 0 & 0 & 0 & 0 & 1 & 2 & 50 & $76(12.4)$ \\
\hline \multirow[t]{2}{*}{ Total of establishments (\%*) } & 0 & 30 & 393 & 2 & 1 & 15 & 0 & 1 & 7 & 8 & 10 & 50 & 124 & \multirow{2}{*}{$\begin{array}{c}611 \\
(100.0)\end{array}$} \\
\hline & $(0)$ & $(6.2)$ & $(80.7)$ & $(0.4)$ & $(0.2)$ & $(3.1)$ & $(0)$ & $(0.2)$ & $(1.4)$ & (1.6) & $(2.1)$ & $(10.3)$ & & \\
\hline
\end{tabular}

*The percentages in parentheses were calculated by assigning the number of the cases/establshments with identified months for SA as $100 \%$.

aged 45-54. Using the Freedman's method for the calendar month of each death, statistically significant departure from uniform distribution was shown only in the cases aged 45-54, with a value of $V_{N}=0.120(p<0.05)$. On the other hand, in the group of workers with SA in months other than March, 31 cases (31.3\%) were concentrated in the period corresponding to positions
$-4,-3$, and -2 . Twenty-two cases of workers aged 44 or younger were included, which accounted for $44.9 \%$ of the workers aged 44 or younger. Using the Freedman's method for the calendar month of each death, statistically significant departure from uniform distribution was found only in the cases aged 44 or younger, with a value of $\mathrm{V}_{\mathrm{N}}=0.214(\mathrm{p}<0.05)$. 


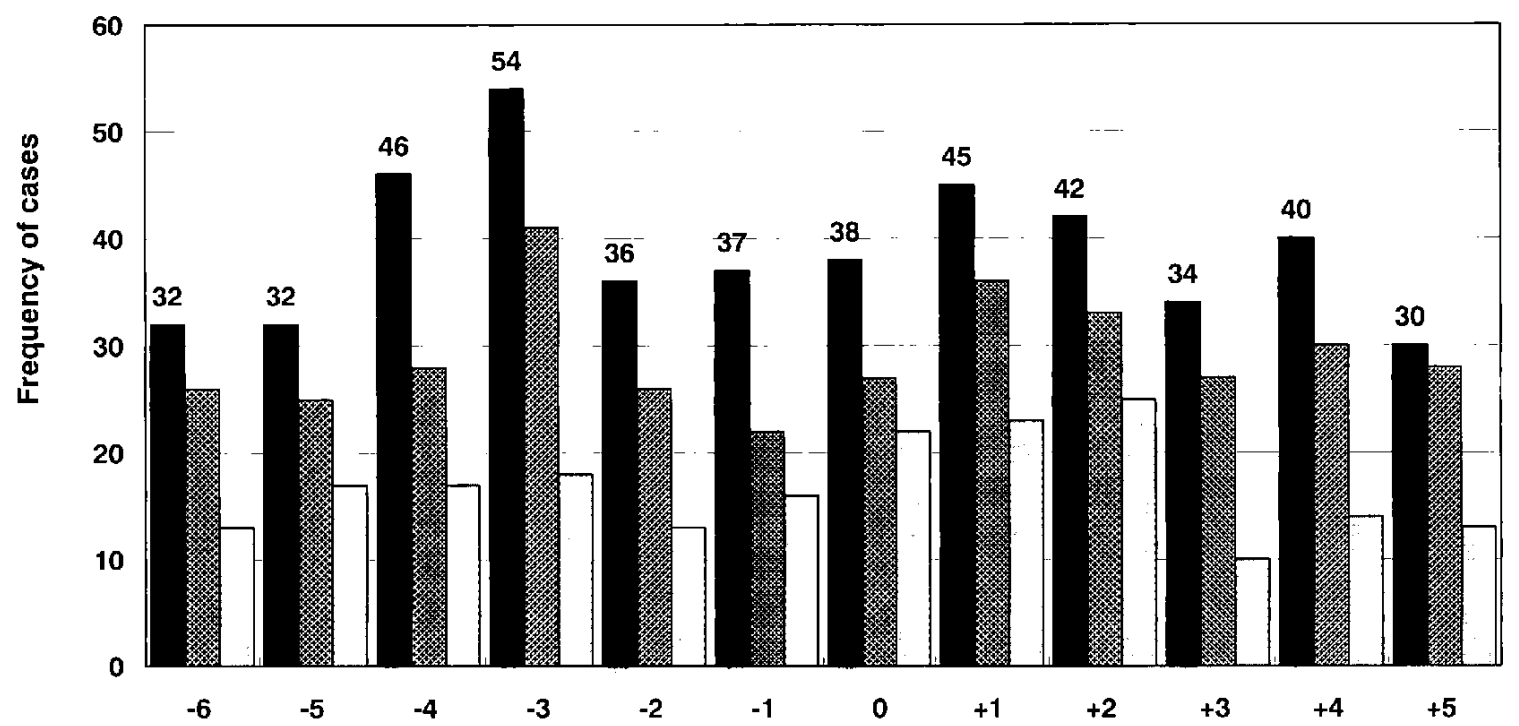

All 466 cases

Cases of cardiovascular origin

$\square$ Cases aged $45-54$

Fig. 2. Monthly differences between sudden death and settlement of accounts among 466 sudden death cases

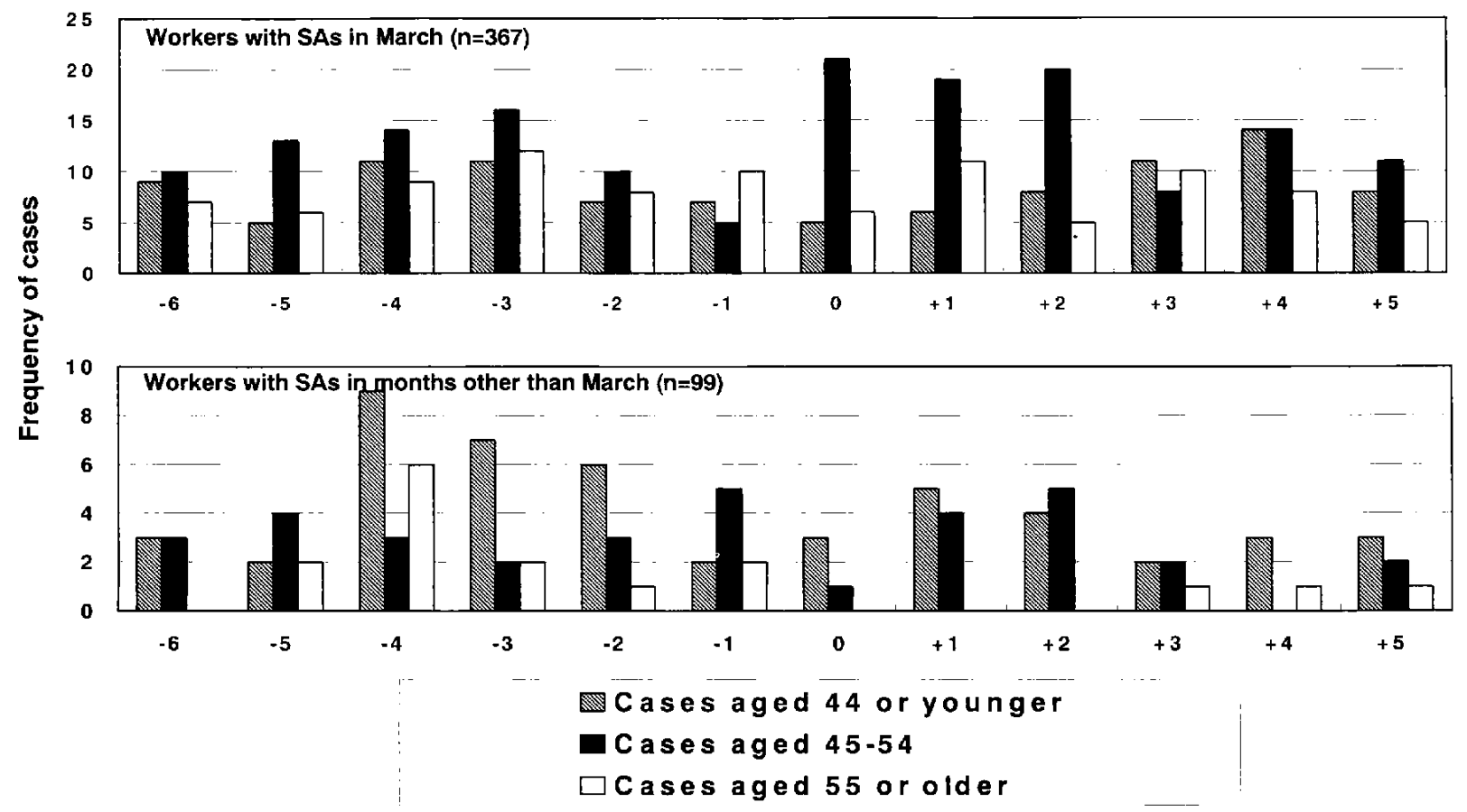

Fig. 3. Monthly difference between sudden death and SA by age groups in the workers whose SAs were in March ( $\mathrm{n}=367$, above) and in the other months $(n=99$, below). Statistically significant departure from uniform distribution was found in the cases aged $45-54$ ( $p<0.05$, above) and in the cases aged 44 or younger ( $p<0.05$, below) by the Freedman's method. 


\section{Discussion}

The seasonal variations in diseases are affected by a variety of factors, physiological, medico-scientific, meteorological, socioeconomic, and so forth. The pattern of variation may differ over time and by country ${ }^{131}$. As for the seasonal variation in sudden death or sudden cardiac death in the developed countries, many authors have asserted that they frequently occurred in the cold season or in winter showing a single peak ${ }^{14.15}$.

To our knowledge, there are a few reports that sudden deaths and cardiovascular diseases among workers increased in the period when stress might increase. Hayashi et al. noted that sudden death occurred more in March and September with relation to work-related stress due to increased workload among male employed workers aged $25-65$ in Niigata, Japan, in $1986-1988^{(6)}$. They also mentioned that the workers might be busiest towards the fiscal-year end and in the period of semi-annual SA in many corporations. Spielberg et al. reported that occurrence of myocardial infarction increased in March and September among workers in Germany for a nineyear period ${ }^{17)}$. They discussed the possibility that the stress due to resumption of work might play a role in triggering myocardial infarction because those two months were just after summer or winter vacation. Therefore, the seasonal variation with two peaks may result from a situation where workers cannot control stressful working conditions.

The distribution of SA was similar to that of sudden death with two peaks, one in March and the other in December. As shown in Fig. 2, however, only a small excess of sudden death was found just after the period of $\mathrm{SA}$, that is, at positions zero, +1 , and +2 , which mainly included the cases who died in March, April, or May. The number of sudden deaths was rather higher at positions -4 and -3 , which mainly included the cases who died in November or December. These facts indicate that a large proportion of the sudden deaths might not necessarily occur in the same periods as the SA or just after the SA.

Nevertheless, as shown in Fig. 3, relatively more sudden deaths occurred at positions zero, +1 , and +2 among workers aged 45-54 with the SA in March. On the other hand, occurrence was not found for workers aged 45-54 with the SA not in March. These facts indicate that the workers aged 45-54 may tend to suffer from adverse health effects in the work environment with the SA in March. Generally speaking, some workers aged 45-54 may be responsible for their workplace as well as family, making the effect greater. It is therefore possible that workers aged 45-54 may have stronger susceptibility to adverse health effects around the SA periods than workers in other age groups.

As for the characteristics of Japanese working style, many workers were loyal to their companies, especially after World War II, and many suffered ill health as a result of accumulated work in busy periods ${ }^{18}$. In addition, Nishiyama and co-author pointed out the fact that the Japanese Production Management system was very problematic, that is, Japanese corporate society created an atmosphere in which doing unpaid overtime work was considered to be a virtue ${ }^{19)}$. Regarding a link between adverse health effects and long working hours, Hayashi et al. noted that 24-h average blood pressure and heart rate increased under the condition of overtime work among Japanese white-collar workers ${ }^{20)}$. Maruyama and Morimoto reported that long working hours might be associated with higher stress among Japanese middle managers ${ }^{21)}$. Sokejima and Kagamimori indicated that extremely long working hours might increase the risk of acute myocardial infarction ${ }^{22)}$. Spurgeon $e$ al. showed that working beyond $50 \mathrm{~h}$ a week might cause adverse health effects $^{23)}$. Thus, in busy periods such as the month of SA, overtime work is prevalent in Japan and may result in an increase in the number of workers suffering ill health.

According to the national statistics in Japan, monthly average working hours in all industry were the highest or the second highest in April, 1988-1992 24-28). In particular, the highest number of working hours in manufacturing industry was that in April in the period, except in 1990 . The monthly and annual average working hours in the industry were as follows: 190.5 and 181.1 in $1988,189.1$ and 179.3 in $1989,185.7$ and 176.6 in 1990, 182.0 and 173.2 in 1991 , and 176.6 and 168.1 in 1992 , respectively. In addition, the monthly average working hours in March, November, and December were higher than each annual average in the period, with a few exceptions. These facts support the association of sudden death with busy period for workers, although the actual working hours of the sudden death cases were not individually measured in this study.

Psychological stress in workers may be increased by factors other than long working hours in Japan. At the fiscal-year end, personnel changes and transfers of workplace are often conducted, which may result in psychological stress and fatigue. In fact, some authors reported that suicide among workers increases in spring, and this might be associated with work-related stress ${ }^{29,30)}$.

Therefore, the two peaks observed in the seasonal variation of sudden death among Japanese workers may be attributed to the following reasons. First, the peak in March-April may be accounted for by workers aged 4554 employed with the SA in March because their health may be more vulnerable due to higher stress than workers in other age groups or those without SA in March. The other peak in November-December may be accounted for not by a limited number of workers but by all workers because Japanese workers are commonly pressed to work harder in the periods near the calendar-year end. Also, 
exposure to cold temperature, a generally established risk factor in cardiovascular disease, and a factor common to all workers, may partly contribute to the peak in November-December.

The most frequent causes of death were categorized as cardiovascular diseases, 362 cases $(74.3 \%)$, and the second most frequent as cerebrovascular diseases, 84 cases $(17.2 \%)$, even though few autopsy reports were available. The distribution of cause of death was not so different from the results of preceding studies on sudden death in Japan, one of which was carried out with postmortem information ${ }^{31)}$ and the others with death certification $^{32.33)}$. Despite the response rate of the current study, $47.3 \%$, such similarity in the distribution of cause of death contributes to the internal validity of the study.

The sudden deaths occurred with annual variation, i.e., 69 cases in $1988(14.1 \%), 92$ cases in $1989(18.9 \%), 91$ cases in $1990(18.7 \%), 108$ cases in $1991(22.1 \%)$, and 128 cases in $1992(26.2 \%)$. The occurrence of annual variation is probably due to the fact that information for more recent years could be more easily reported. Three establishments actually informed the researchers that they could not report the deaths which had occurred in 1988 and in 1989 because the capacity of their data recording system was limited to holding only data for the past three years. If other establishments had such limits, some sudden death cases may have been excluded.

The results shown above may not necessarily reflect the aspects of disease incidence and/or mortality among the whole working population in Japan because our investigation was restricted to establishments with one thousand or more workers. According to the results of the 1991 Establishment Census, the number of workers employed in the establishments and that of the total number of workers were 2,631,051 and 55,013,776, respectively $y^{6)}$. Thus, the proportion of the working population in this study was estimated to be $4.78 \%$ of privately owned Japanese establishments. In addition, the number of establishments with one thousand or more workers and that of all establishments were 1,300 and $6,559,377$, respectively ${ }^{6}$. Thus, the proportion of establishments in this study was approximately $0.02 \%$ of all privately owned Japanese establishments. The external validity may be limited because the study subjects were a part of the entire Japanese working population.

In this study, it was impossible to estimate the incidence of sudden death among Japanese workers because the person-year of workers could not be calculated in each establishment. Therefore, we substituted frequency for incidence. Under the assumption of a stable target population, the frequency can be of use for an epidemiological survey.

In conclusion, we carried out the questionnaire survey to investigate the seasonal variation in the occurrence of sudden death among workers in large-scale establishments in Japan between 1988 and 1992. Of 488 male sudden death cases reported, 362 were categorized into those of cardiovascular origin. Two peaks of occurrence of sudden death, in March-April and in November-December, were found among all of the 488 sudden death cases and the 362 cardiac cases with statistically significant departure from the uniform monthly distribution ( $p<0.01$ ). The peak in March-April may be accounted for by the increased number of sudden deaths in workers aged 45-54, whereas the peak in November-December may be accounted for by the increased number of sudden deaths for all, not a limited number of workers. Because both peaks were associated with busy periods for workers in Japan, work environmental factors may affect the seasonal variation as shown by the distinctive shape of the curve of sudden death among workers.

Acknowledgments: This study was supported by a grant from the Ministry of Labor, Japan. The authors thank the occupational health staffs involved for their cooperation in this study.

\section{References}

1) Uehata $T$. Long working hours and occupational stressrelated cardiovascular attacks among middle-aged workers in Japan. J Hum Ergol (Tokyo) 1991; 20: 147 153.

2) Hoshuyama T, Sacki S, Takahashi K, Okubo T. A descriptive epidemiology on sudden death among workers. J UOEH 1992; 14: 219-225 (in Japanese).

3) Sakai A. Sudden deaths among male employees: A sixyear epidemiological survey. J Cardiol 1990; 20: 957961 (in Japanese).

4) Willich SN, Lowel H, Lewis M, Hormann A, Arntz MR, Keil U. Weekly variation of acute myocardial infarction increased Monday risk in the working population. Circulation 1994; 90: 87-93.

5) Kodansha Ltd. JAPAN An Illustrated Encyclopedia 1993.

6) Statistics Bureau, Management and Coordination Agency. 1991 Establishment Census of Japan. 1992.

7) WHO Scientific Group. Sudden Cardiac Death. WHO Tech Rep Ser 1985; 726: 5-6.

8) Snedecor GW, Cochran WG. Statistical Methods. 8th ed. Iowa: Iowa State University Press, 1989.

9) Freedman LS. The use of a Kolmogorov-Smirnov type statistic in testing hypotheses about seasonal variation. J Epidemiol Community Health 1979; 33: 223-228.

10) Nihon Keizai Shimbun Inc. Nikkei; Annual Corporation Reports (Kaisha Nenkan Jojogaisha-ban) 1990.

11) Nihon Keizai Shimbun Inc. Nikkei; Annual Corporation Reports, Unlisted- vol. 1 (Kaisha Nenkan Mijojogaisha-ban, Jo-kan) 1989.

12) Nihon Keizai Shimbun Inc. Nikkei; Annual Corporation Reports, Unlisted- vol. 2 (Kaisha Nenkan Mijojogaisha-ban, Ge-kan) 1989. 
13) Sakamoto-Momiyama M. Seasonality in Human Mortality A Medico-Geographical Study. Tokyo: University of Tokyo Press, 1977.

14) Kuller LH, Talbott EO, Robinson C. Environmental and psychosocial determinants of sudden death. Circulation 1987; 76 (suppl I): I177-I185.

15) Woodhouse PR, Khaw KT, Plummer M, Foley A, Meade TW. Seasonal variations of plasma fibrinogen and factor VII activity in the elderly: winter infections and death from cardiovascular disease. Lancet 1994; 343: 435-439.

16) Hayashi S, Toyoshima $H$, Sato $T$, Tanabe N, Seki N, Miyanishi K. Seasonal Variation in the Incidence of Sudden Death According to Occupation of Householder in Japan. Jpn Circ J 1997; 61: 814-818.

17) Spielberg C, Falkenhahn D, Willich SN, Wegscheider $K$, Voller H. Circadian, day-of-week, and seasonal variability in myocardial infarction: Comparison between working and retired patients. Am Heart J 1996; 132: 579-585.

18) Tokunaga Y. Overwork and Health Injuries. Economic Analysis (Keizai Bunseki) 1994; 133: 75-80 (in Japanese)

19) Nishiyama K, Johnson JV. Karoshi-Death from overwork: Occupational health consequences of Japanese production management. Int J Health Sciences 1997; 27: 625-641.

20) Hayashi T, Kobayashi Y, Yamaoka K, Yano E. Effect of overtime work on 24-hour ambulatory blood pressure. J Occup Environ Med 1996; 38: 1007-1011.

21) Maruyama $S$, Morimoto $K$. Effects of long workhours on life-style, stress and quality of life among intermediate Japanese managers. Scand J Work Environ Health 1996; 22: 353-359.

22) Sokejima $S$, Kagamimori $S$. Working hours as a risk factor for acute myocardial infarction in Japan: casecontrol study. Br Med J 1998; 317: 775-780.

23) Spurgeon A, Harrington JA, Cooper CL. Health and safety problems associated with long working hours: a review of the current position. Occup Environ Med 1997; 54: 367-375.
24) Statistics Bureau, Management and Coordination Agency. Average monthly hours worked per regular worker by industry. Japan Statistical Year Book (Nippon Tokei Nenkan) 1989; 110.

25) Statistics Bureau, Management and Coordination Agency. Average monthly hours worked per regular worker by industry. Japan Statistical Year Book (Nippon Tokei Nenkan) 1990; 110.

26) Statistics Bureau, Management and Coordination Agency. Average monthly hours worked per regular worker by industry. Japan Statistical Year Book (Nippon Tokei Nenkan) 1991; 110.

27) Statistics Bureau, Management and Coordination Agency. Average monthly hours worked per regular worker by industry. Japan Statistical Year Book (Nippon Tokei Nenkan) 1992; 110.

28) Statistics Bureau, Management and Coordination Agency. Average monthly hours worked per regular worker by industry. Japan Statistical Year Book (Nippon Tokei Nenkan) 1993/94; 126.

29) Araki S, Aono H, Shikata I, Mitsukuni Y. Scasonal variation in suicide by cause and sex. J Biosoc Sci 1986; 18: $471-478$.

30) Egashira K, Abe K. Secular Trends of Suicide Seasonality: A Comparative Study of Various Countries. Jpn J Biometeor 1988; 25: 97-109 (in Japanese).

31) Kawai C. Studies on the occurrence of sudden death. In: National Cardiovascular Center, ed. Annual Report of the Research on Cardiovascular Diseases 1987. Osaka: National Cardiovascular Center, 1988: 675 (in Japanese).

32) Toyoshima H, Hayashi $\mathbf{S}$, Miyanishi $K$, et al. An epidemiology of sudden death based on the information of death certificates in Niigata Prefecture, 1984-86. Jpn Med J 1991; 3444: 46-51 (in Japanese).

33) Kiryu Y, Suzuki S, Hosokai H, Tamura S. A casecontrol study on the risk factors of sudden death. An analysis of 44 cases in a company by health care records. Jpn J Ind Health 1994; 36: 16-23 (in Japanese). 